\title{
Is mediated embodiment the response to embodied cognition?
}

\section{Laura Aymerich-Franch}

\section{Mediated embodiment: a non-human body to be in the world}

There is an increasing tendency in emerging technologies to progressively immerse and couple the human body to the interface (Biocca, 1997). Avatar embodiment in virtual reality and humanoid robot embodiment are the most representative forms of this phenomenon, which can be described as mediated embodiment. Similar concepts have been used to describe related phenomena (Biocca, 1997, 2002; Kilteni, Groten, \& Slater, 2012; Lee, 2004; Ratan, 2010), but a more global definition is missing which includes all current and future embodiment technologies and conceptualizes these systems as a whole. As a working definition, mediated embodiment is introduced here as the technologically induced illusion of experiencing the body of an avatar as one's own, independently of the technology used to produce the illusion (Author, 2017). Embodiment indicates the existence in the world through a body (Csordas, 1999), while the adjective mediated is related to the use of communication technologies. In mediated embodiment, users adopt an artificial body of a digital or a robot avatar from which they experience the virtual or physical environment in first person. The artificial body can be similar or drastically different from the human body (Aymerich-Franch, 2012) and it can even be non-physical (i.e., virtual).

The central claim of embodied cognition is that cognition is highly dependent on the characteristics of the physical body and its interactions with the world (Lakoff \& Johnson, 1999; Seitz, 2000; Shapiro, 2004, 2007, 2010; Thelen, Schöner, Scheier, \& Smith, 2001; Thelen, 1995; Thelen \& Smith, 1994; Wilson, 2002; Wilson \& Foglia, 2011). According to this view, the particular form of embodiment (i.e., the characteristics of the body) of an organism and its sensory-motor capacities determine the way the environment appears to that organism as well as the way in which the organism can interact in it (Lakoff \& Johnson, 1999; Varela, Thompson, \& Rosch, 1991; Wilson \& Foglia, 2011). From these premises, it follows that, if an organism of body structure 
type-A embodies a body with substantially different body properties (i.e., body structure type-B), significant differences should emerge both at the low and high cognitive levels compared to an original organism of body structure type-A.

An important drawback to test this postulate is that, under normal circumstances, organisms cannot "abandon" their bodies to embody a different body. However, in a successful mediated embodiment experience, users feel their sense of self located within the boundaries of their avatar body and experience it as if it was their own (Ehrsson, 2007; Kilteni, Maselli, Kording, \& Slater, 2015; Lenggenhager, Tadi, Metzinger, \& Blanke, 2007; Petkova \& Ehrsson, 2008; Slater, Spanlang, Sanchez-Vives, \& Blanke, 2010). The transformations that take place during these experiences at the cognitive processing level (Ahn, Le, \& Bailenson, 2013; Aymerich-Franch, Kizilcec, \& Bailenson, 2014; Groom, Bailenson, \& Nass, 2009; Hershfield et al., 2011; Kilteni, Bergstrom, \& Slater, 2013; Maister, Slater, Sanchez-Vives, \& Tsakiris, 2014; Rosenberg, Baughman, \& Bailenson, 2013; Steptoe, Steed, \& Slater, 2013; Won, Bailenson, Lee, \& Lanier, 2015; Yee \& Bailenson, 2007) could reveal to what extent the specific properties of the body determine cognition. Following this, if a human being (i.e., organism of body structure type-A) embodies an avatar of substantially different body properties (i.e., body structure type-B) and interacts in the environment with that body, significant differences should emerge both at the low and high cognitive level compared to a regular human that interacts in the same environment.

\section{The technologically created experience of "becoming someone else"}

First-person perspective is a fundamental requirement to induce sense of embodiment in an avatar (González-Franco, et al., 2010; Maselli and Slater, 2013; Slater et al., 2010). Head-mounted displays (HMDs) are used to provide visual feedback from the avatar's eyes and occlude participant's vision from the real world (Fig.1A). In virtual reality, HMDs display the virtual environment whereas in robot embodiment the HMD displays real time video feedback from the robot's eyes. Head movements of the embodied user are tracked and synchronized to those of the avatar to offer real time visual feedback of the avatar surroundings in accordance to those movements. Control of the avatar body movement can be achieved in multiple ways (Fig.2), such as body motion tracking and 
synchronization, brain-computer interface, eye-tracking, or a joystick (Alimardani et al., 2013; Aymerich-Franch et al., 2015, 2016a, 2016b; Cohen et al., 2012, 2014; Kishore et al., 2014; Nishio et al., 2012). Auditory feedback is implemented with the use of headsets or speakers and haptic feedback can be implemented with the aid of different sort of haptic devices that facilitate grasping and moving objects, experiencing a texture, or receiving force feedback (Fox et al., 2009; Stone, 2001).

\section{-- Figure 1 --}

Figure 1. Mediated embodiment process. Users wear a head-mounted display (A) which provides first-person audiovisual perspective from the avatar body and blocks vision from the physical world. Users embody an avatar in virtual reality (B) or in a physical environment (C) and experience its body and its surroundings in first person. Avatars can also be non-anthropomorphic living beings or objects (D).

\section{-- Figure 2 --}

Figure 2. Example of embodiment setup. An embodied user (right) wears a head-mounted display that provides visual feedback from the avatar (left) perspective and blocks vision from the physical environment. The user's head and body movements are synchronized to those of the avatar. The user can interact in the environment through the body of the avatar.

Avatars can be digital (virtual reality) or physical (robots). They can present humanlooking appearances (Fig.1B), non-human looking appearances (Fig.1C), or even have non-anthropomorphic shapes (Fig.1D). In order to create identification with the avatar's body, users are able to see its limbs (if they have any) and part of its body when they look down. Full-body identification is obtained with the use of reflecting surfaces such as mirrors (Aymerich-Franch et al., 2015, 2016a, 2016b; Aymerich-Franch, Kizilcec, \& Bailenson, 2014; González-Franco, Pérez-Marcos, Spanlang, \& Slater, 2010). Table 1 synthetizes the technical commonalities used by mediated embodiment systems to create the sense of embodiment. 
Table 1. Technical commonalities used by mediated embodiment systems to create the sense of embodiment.

\section{Empirical evidence of full-body ownership transfer in artificial embodiment}

The rubber-hand illusion experiment (Botvinick \& Cohen, 1998) has been largely used to demonstrate that humans are able to experience body ownership of an artificial limb. As an extension of this paradigm, full-body ownership illusions involving virtual and fake bodies have been used to show that sense of body ownership may also be transferred towards a full body (Maselli \& Slater, 2014; Petkova \& Ehrsson, 2008; Slater et al., 2010). Beyond that, full-body ownership illusions have recently been proposed as a paradigm to study self-consciousness and, specifically, as a way to demonstrate that the spatial unity between self and body can be disrupted (Ehrsson, 2007; Guterstam \& Ehrsson, 2012; Lenggenhager et al., 2007). Studies following this paradigm suggest that multisensory correlations altogether with a manipulated visual perspective are enough to transfer the perceived sense of self-location to an illusory body (Ehrsson, 2007; Guterstam \& Ehrsson, 2012; Lenggenhager et al., 2007).

During mediated embodiment experiences, users feel present in the location of their avatars and experience their avatars as if they were their real selves (Lee, 2004; Ratan, 2010). The feeling of Presence (Heeter, 1992; Lee, 2004; Lombard \& Ditton, 1997; Steuer, Biocca, \& Levy, 1995; Steuer, 1992) is one of the most researched areas in mediated embodiment. When users feel present in the location of the avatar, they behave and emotionally respond similarly to how they do in reality (Sanchez-Vives \& Slater, 2005). Also, they tend to treat virtual people as if they were real people, showing social responses such as keeping similar interpersonal distance (Bailenson et al., 2001; Bailenson et al., 2003; Garau et al., 2005).

Furthermore, it has been shown that humans are able to integrate body-parts that do not correspond to their real body structure, such as extra limbs (Won et al., 2015) or tails (Steptoe et al., 2013), or experience body ownership transfer towards a nonhuman looking humanoid robot (Aymerich-Franch et al., 2015, 2016a, 2016b). Previous 
works also suggest that people embodied in virtual bodies are able to rapidly learn to use a novel body with substantially different body schemas to successfully complete a task (Won et al., 2015).

Finally, there is also evidence that avatar embodiment may cause transformations in users' attitudes and behavior that can persist even after the experience of embodiment (Aymerich-Franch, Kizilcec \& Bailenson, 2014; Groom, Bailenson, \& Nass, 2009; Hershfield, et al., 2011; Peck, Seinfeld, Aglioti, \& Slater, 2013; Rosenberg et al., 2013; Won, Bailenson, Lee, \& Lanier, 2015; Yee \& Bailenson, 2007).

\section{Mediated embodiment as a methodological tool for embodied cognition}

Even though embodied cognition research program has been formulated in several different ways, a series of central assumptions can be extracted and examined under the framework of mediated embodiment:

1. The form of embodiment defines and constrains cognition (Cowart, 2004; Shapiro, 2004, 2007, 2010; Thelen et al., 2001; Thelen, 1995; Thelen \& Smith, 1994; Wilson, 2002; Wilson \& Foglia, 2011). The specifications of the body determine how an organism performs goal-directed actions in the environment and why it chooses one option over another to carry out a specific task (Cowart, 2004). In relation to this, embodied cognition also sustains that some forms of cognition should appear more naturally whereas others should not emerge depending on the characteristics of the body (Wilson \& Foglia, 2011). Therefore, if an organism of body structure type-A is artificially embodied in an avatar of body type-B, and another organism of body structure type- $A$ is artificially embodied in an avatar of body type-C, different options to perform goal-directed actions should emerge based on the differences between B and C. In addition, significant differences linked to the specific characteristics of each form of embodiment should emerge at the cognitive level in the organism embodied in $B$ that should not appear in the organism embodied in C, and vice versa (postulate 1). 
2. Cognition results from the interaction of the body with the environment (Clark, 1999; Cowart, 2004; Engel, Maye, Kurthen, \& König, 2013; Glenberg, Witt, \& Metcalfe, 2013; Shapiro, 2010; Thelen et al., 2001; Thelen, 1995; Thelen \& Smith, 1994). Each organism uses its specific properties to interact with the environment and retains the ways in which it needs to perform based on the experience obtained during these interactions (Thelen et al., 2001; Thelen, 1995; Thelen \& Smith, 1994). Thus, after repeatedly experiencing a situation, the organism categorizes and recognizes it and is able to apply the best strategy to achieve a specific goal (e.g. reaching an object) linked to that situation (Thelen et al., 2001; Thelen, 1995; Thelen \& Smith, 1994). Consequently, if an organism of body structure type- $A$ is artificially embodied in an avatar of body type-B and transported to a new environment where only $B$ is prepared to interact, this organism should learn how to perform actions with the body type-B, even if its previous knowledge made no sense to survive in the new environment. Likewise, this organism should evolve towards recognizing and categorizing situations and correctly applying the appropriate strategy to each situation. Also, if two organisms of body structure type-A that are embodied in an avatar of body type$B$ are required to perform different types of tasks, they should perceive the environment differently, depending on the type of task that each one performs (postulate 2).

3. The unique form of embodiment and sensorimotor capacities of an organism determine how each organism perceives the external environment (Cowart, 2004; Shapiro, 2007, 2010; Varela, Thompson, \& Rosch, 1991; Wilson \& Foglia, 2011). Therefore, if an organism of body structure type-A is artificially embodied in an avatar of body type- $B$, the way it perceives the external environment should depend on the body characteristics that define the avatar. Also, the way the organism perceives the external environment should be substantially different from the way an original organism of body-structure type-A perceives it (postulate 3).

4. Organisms are highly predisposed towards constant bodily and mind restructuring and their boundaries are continually negotiable (Clark, 2007). 
During these episodes of transformative restructuring, new equipment can become incorporated into the thinking and acting systems of the organisms (Clark, 2007). Following this, if an organism of body structure type-A is artificially embodied in an avatar of body type-B, its mind and body boundaries should rapidly restructure to incorporate the body of the avatar as part of the global organism (postulate 4).

5. The understanding of other organisms' minds is predominantly based on the motor expertise underlying the capacity of the organism to act (Gallese \& Sinigaglia, 2011; Wilson \& Foglia, 2011). Thus, an organism with body structure type-A that is embodied in an avatar of body type-B should be able to better recognize and understand the needs, intentions, and behaviors of organisms of body structure type-B compared to a similar organism that is not embodied in an avatar of body type-B. Also, this organism should be more capable of interacting with organisms of body structure type-B as well as of helping them achieve their goals than an organism that is not embodied in an avatar of body type-B (postulate 5).

6. Concept acquisition and language comprehension are determined and constrained by the properties of the body and the way in which it interacts with the environment (Gallese \& Sinigaglia, 2011; Glenberg, 1997; Glenberg et al., 2013; Kaschak \& Glenberg, 2000; Lakoff \& Johnson, 1999; Lakoff \& Johnson, 1980; Markman \& Brendl, 2005). Consequently, an organism of body structure type-A that is embodied in an avatar of body type-B should be able to understand the meaning of certain concepts linked to the experience of interacting in the environment during embodiment in B or even able to generate new concepts that a regular organism of body structure type-A might not be able to understand. Also, this organism should find it less difficult to understand a description of actions experienced during embodiment in $B$ for which organisms of body structure type-A are not suited (postulate 6).

The six postulates described above could be tested with the use of mediated embodiment technologies. In mediated embodiment, nearly all properties of the avatar 
body and the avatar's environment have the potential to be modified. Different systems of mediated embodiment (i.e. digital avatars in virtual environments or robot avatars in physical environments) enable different property transformations. Modifications with respect to the original body can be minimal to radical. Among many other properties of the avatar body that can be altered are material, shape, volume, weight, height, elasticity, color, strength, moving capabilities, or moving speed. The way the external environment is perceived can be altered in physicality (i.e. interactions can take place in a physical or in a virtual environment), depth / number of dimensions, scale with respect to the body, color, or even time, to mention the most relevant.

In digital environments, experimental subjects could for instance embody a cubeshaped digital avatar (Fig. 1D) with no limbs that moved when the subject blinked. The embodied subjects might need to find out this capability by themselves and learn to control it. Experimental subjects could also embody digital avatars with extended or reduced perception capacities, with new senses, or with new capabilities such as time freezing. In physical environments, experimental subjects could for instance embody robot avatars with the capacity of flying, resisting underwater, or having super strength to move heavy objects.

\section{Concluding remarks}

I have argued that the adoption of full-body mediated embodiment systems might be used as a sophisticated methodological tool to empirically test the assumptions defended from the embodied cognition approach.

A further advantage of this methodological approach is that in some mediated embodiment systems the physical body may remain in a fixed position during embodiment while the virtual body interacts in the environment, which facilitates certain types of measurements such as brain activity. There are also some caveats to be mentioned. One is that mediated embodiment systems are still evolving to provide successful experiences of embodiment in which users fully self-locate and identify with the avatar body to the point that they temporarily forget their human body. Also, with the current mediated embodiment systems, long periods of embodiment might produce fatigue for the user. However, the technology behind these systems is rapidly 
evolving. Another disadvantage is that even if an organism is embodied in a body with radically different properties, this organism will still maintain certain properties and cognitive processes from the original body. However, that should not prevent researchers from being able to observe the differences between subjects embodied in different types of bodies. The possibility of studying infants (Thelen \& Smith, 1994) under conditions of mediated embodiment could minimize this drawback.

The methodological approach of mediated embodiment could answer fundamental questions that the embodied cognition approach has not been able to verify under more traditional methodologies. Even more fascinating, embodying humans into radically different avatar bodies might reveal new phenomena that passed unnoticed or was not comprehended before, given the constraints of human embodiment on cognition.

\section{Acknowledgments}

This project has received funding from the European Union with the Marie Curie IOF Fellowship project XXX.

\section{References}

Author (2017). XXX

Ahn, S. J. (Grace), Le, A. M. T., \& Bailenson, J. (2013). The Effect of Embodied Experiences on Self-Other Merging, Attitude, and Helping Behavior. Media Psychology, 16(1), 7-38. doi:10.1080/15213269.2012.755877

Alimardani, M., Nishio, S., \& Ishiguro, H. (2013). Humanlike robot hands controlled by brain activity arouse illusion of ownership in operators. Scientific Reports, 3, 2396. doi:10.1038/srep02396

Aymerich-Franch, L. (2012). Can we identify with a block? Identification with nonanthropomorphic avatars in virtual reality games. Proceedings of the International Society for Presence Research Annual Conference. October 24-26, Philadelphia, Pennsylvania, USA. 
Aymerich-Franch, L., Kizilcec, R. F., \& Bailenson, J. N. (2014). The Relationship between Virtual Self Similarity and Social Anxiety. Frontiers in Human Neuroscience, 8(November), 1-10. doi:10.3389/fnhum.2014.00944

Aymerich-Franch, L., Petit, D., Ganesh, G., \& Kheddar, A. (2015). Embodiment of a humanoid robot is preserved during partial and delayed control. In 2015 IEEE International Workshop on Advanced Robotics and its Social Impacts. Lyon, France.

Aymerich-Franch, L., Petit, D., Ganesh, G., \& Kheddar, A. (2016a). In a robot's body: Illusory bi-location of the self during artificial body reduplication. Communication presented at the International Communication Association Conference (ICA), June 9-13, Fukuoka, Japan.

Aymerich-Franch, L., Petit, D., Ganesh, G., \& Kheddar, A. (2016b). In a robot's body: Illusory bi-location of the self during artificial body reduplication. Communication to be presented at the International Communication Association Conference (ICA), June 9-13, Fukuoka, Japan.

Bailenson, J. N., Blascovich, J., Beall, A. C., \& Loomis, J. M. (2001). Equilibrium Theory Revisited: Mutual Gaze and Personal Space in Virtual Environments. Presence: Teleoperators and Virtual Environments, 10(6), 583-598.

Bailenson, J. N., Blascovich, J., Beall, A. C., \& Loomis, J. M. (2003). Interpersonal distance in immersive virtual environments. Personality and Social Psychology Bulletin, 29(7), 819-833.

Biocca, F. (1997). The Cyborg's Dilemma: Progressive Embodiment in Virtual Environments Minding the Body, the Primordial Communication Medium. JCMC, 3(September), 1-29. doi:10.1111/j.1083-6101.1997.tb00070.x

Biocca, F. (2002). The evolution of interactive media. In M. C. Green, J. J. Strange, \& T. C. Brock (Eds.), Narrative impact. Social and cognitive foundations (pp. 97-130). Taylor \& Francis.

Botvinick, M., \& Cohen, J. (1998). Rubber hands "feel" touch that eyes see. Nature, 391(6669), 756. doi:10.1038/35784 
Clark, A. (1999). An embodied cognitive science? Trends in Cognitive Sciences, 3(9), 345-351. doi:10.1016/S1364-6613(99)01361-3

Clark, A. (2006). Language, embodiment, and the cognitive niche. Trends in Cognitive Sciences, 10(8), 370-374. doi:10.1016/j.tics.2006.06.012

Clark, A. (2007). Re-inventing ourselves: The plasticity of embodiment, sensing, and mind. Journal of Medicine and Philosophy, 32(3), 263-282.

Cohen, O., Druon, S., Lengagne, S., Mendelsohn, A., Malach, R., Kheddar, A., \& Friedman, D. (2012). fMRI robotic embodiment: A pilot study. 2012 4th IEEE RAS \& EMBS International Conference on Biomedical Robotics and Biomechatronics (BioRob), 314319. doi:10.1109/BioRob.2012.6290866

Cohen, O., Druon, S., Lengagne, S., Mendelsohn, A., Malach, R., Kheddar, A., \& Friedman, D. (2014). fMRI-Based Robotic Embodiment: Controlling a Humanoid Robot by Thought Using Real-Time fMRI. Presence: Teleoperators and Virtual Environments, 23(3), 229241.

Cowart, M. (2004). Embodied Cognition. Internet Encyclopedia of Philosophy. Retrieved from: www.iep.utm.edu.

Csordas, T. J. (1999). Embodiment and cultural phenomenology. In Perspectives on embodiment: The intersections of nature and culture (pp. 143-162).

Ehrsson, H. H. (2007). The experimental induction of out-of-body experiences. Science (New York, N.Y.), 317(5841), 1048. doi:10.1126/science.1142175

Engel, A. K., Maye, A., Kurthen, M., \& König, P. (2013). Where's the action? The pragmatic turn in cognitive science. Trends in Cognitive Sciences, 17(5), 202-209. doi:10.1016/j.tics.2013.03.006

Fox, J., Arena, D., \& Bailenson, J. N. (2009). Virtual Reality: A Survival Guide for the Social Scientist. Journal of Media Psychology, 21(3), 95-113. doi:10.1027/1864-1105.21.3.95

Gallese, V., \& Sinigaglia, C. (2011). What is so special about embodied simulation? Trends in Cognitive Sciences, 15(11), 512-519. doi:10.1016/j.tics.2011.09.003 
Garau, M., Slater, M., Pertaub, D. P., \& Razzaque, S. (2005). The responses of people to virtual humans in an immersive virtual environment. Presence: Teleoperators and Virtual Environments, 14(1), 104-116.

Glenberg, A. M. (1997). What memory is for: Creating meaning in the service of action. Behavioral and brain sciences, 20(01), 41-50.

Glenberg, A., Witt, J., \& Metcalfe, J. (2013). From the Revolution to Embodiment 25 Years of Cognitive Psychology. Perspectives on Psychological Science, 8(5), 573-585. doi:10.1177/1745691613498098

González-Franco, M., Pérez-Marcos, D., Spanlang, B., \& Slater, M. (2010). The Contribution of Real-Time Mirror Reflections of Motor Actions on Virtual Body Ownership in an Immersive Virtual Environment, 111-114.

Groom, V., Bailenson, J. N., \& Nass, C. (2009). The influence of racial embodiment on racial bias in immersive virtual environments. Social Influence, 4(3), 231-248. doi:10.1080/15534510802643750

Guterstam, A., \& Ehrsson, H. H. (2012). Disowning one's seen real body during an outof-body illusion. Consciousness and Cognition, 21(2), 1037-42. doi:10.1016/j.concog.2012.01.018

Heeter, C. (1992). Being there: The subjective experience of presence. Presence: Teleoperators and Virtual Environments, 1(2), 262 - 271. doi:10.1109/VRAIS.1995.512482

Hershfield, H.E., Goldstein, D.G., Sharpe, W.F., Fox, J., Yeykelis, L., Carstensen, L.L., \& Bailenson, J.N. (2011). Increasing saving behavior through age-progressed renderings of the future self. Journal of Marketing Research, 48, S23-S37.

Kaschak, M. P., \& Glenberg, A. M. (2000). Constructing Meaning: The Role of Affordances and Grammatical Constructions in Sentence Comprehension. Journal of Memory and Language, 43(3), 508-529. doi:10.1006/jmla.2000.2705 
Kilteni, K., Bergstrom, I., \& Slater, M. (2013). Drumming in immersive virtual reality: the body shapes the way we play. Visualization and Computer Graphics, IEEE Transactions on, 19(4), 597-605.

Kilteni, K., Groten, R., \& Slater, M. (2012). The Sense of Embodiment in Virtual Reality. Presence: Teleoperators and Virtual Environments, 21(4), 373-387. doi:10.1162/PRES_a_00124

Kilteni, K., Maselli, A., Kording, K. P., \& Slater, M. (2015). Over my fake body: body ownership illusions for studying the multisensory basis of own-body perception. Frontiers in Human Neuroscience, 9, 141. doi:10.3389/fnhum.2015.00141

Kishore, S., González-Franco, M., Hintemüller, C., Kapeller, C., Guger, C., Slater, M., \& Blom, K. J. (2014). Comparison of SSVEP BCl and Eye Tracking for Controlling a Humanoid Robot in a Social Environment. Presence: Teleoperators and Virtual Environments, 23(3), 242-252.

Lakoff, G., \& Johnson, M. (1980). Metaphors We Live By. Chicago and London: The University of Chicago.

Lakoff, G., \& Johnson, M. (1999). Philosophy In the Flesh: The Embodied Mind And Its Challenge To Western Thought. New York, NY: Basic Books.

Lee, K. M. (2004). Presence, Explicated. Communication Theory, 14(1), 27-50. doi:10.1093/ct/14.1.27

Lenggenhager, B., Tadi, T., Metzinger, T., \& Blanke, O. (2007). Video ergo sum: manipulating bodily self-consciousness. Science (New York, N.Y.), 317(5841), 1096-9. doi:10.1126/science.1143439

Lombard, M., \& Ditton, T. (1997). At the Heart of it All. The Concept of Presence. Journal of Computer-Mediated Communication, 3(September), 20. doi:10.1093/cid/cir583

Maister, L., Slater, M., Sanchez-Vives, M. V., \& Tsakiris, M. (2014). Changing bodies changes minds: owning another body affects social cognition. Trends in Cognitive Sciences, 19(1), 6-12. doi:10.1016/j.tics.2014.11.001 
Markman, A. B., \& Brendl, C. M. (2005). Constraining theories of embodied cognition. Psychological Science, 16(1), 6-10. doi:10.1111/j.0956-7976.2005.00772.x

Maselli, A., \& Slater, M. (2013). The building blocks of the full body ownership illusion. Frontiers in Human Neuroscience, 7(March), 83.

Maselli, A., \& Slater, M. (2014). Sliding perspectives: dissociating ownership from selflocation during full body illusions in virtual reality. Frontiers in Behavioral Neuroscience, 8(September), 1-19. doi:10.3389/fnhum.2014.00693

Nishio, S., Watanabe, T., Ogawa, K., \& Ishiguro, H. (2012). Body ownership transfer to Teleoperated Android Robot. Ge at al., (eds). ICSR 2012, LNAI 7621, 398-407. SpringerVerlag Berlin.

Peck, T. C., Seinfeld, S., Aglioti, S. M., \& Slater, M. (2013). Putting yourself in the skin of a black avatar reduces implicit racial bias. Consciousness and cognition, 22(3), 779-787.

Petkova, V. I., \& Ehrsson, H. H. (2008). If I were you: perceptual illusion of body swapping. PloS One, 3(12), e3832. doi:10.1371/journal.pone.0003832

Ratan, R. (2010). Self-Presence, Explicated. Paper presented at the 60th Annual Conference of the International Communication Association, Singapore.

Rosenberg, R. S., Baughman, S. L., \& Bailenson, J. N. (2013). Virtual Superheroes: Using Superpowers in Virtual Reality to Encourage Prosocial Behavior. PLoS ONE, 8(1), 1-9. doi:10.1371/journal.pone.0055003

Sanchez-Vives, M. V., \& Slater, M. (2005). From presence to consciousness through virtual reality. Nature Reviews Neuroscience, 6(4), 332-339.

Seitz, J. A. (2000). The bodily basis of thought. New ideas in Psychology, 18(1), 23-40.

Shapiro, L. (2004). The mind incarnate. The MIT Press.

Shapiro, L. (2007). The Embodied Cognition Research Programme. Philosophy Compass, 2(2), 338-346. doi:10.1111/j.1747-9991.2007.00064.x

Shapiro, L. (2010). Embodied Cognition. Routledge. 
Slater, M., Spanlang, B., Sanchez-Vives, M. V, \& Blanke, O. (2010). First person experience of body transfer in virtual reality. PloS One, 5(5), e10564. doi:10.1371/journal.pone.0010564

Steptoe, W., Steed, A., \& Slater, M. (2013). Human tails: ownership and control of extended humanoid avatars. IEEE Transactions on Visualization and Computer Graphics, 19(4), 583-90. doi:10.1109/TVCG.2013.32

Steuer, J. (1992). Defining Virtual Reality: Dimensions Determining Telepresence. Journal of Communication, 42(4), 73-93. doi:10.1111/j.1460-2466.1992.tb00812.x

Steuer, J., Biocca, F., \& Levy, M. R. (1995). Defining virtual reality: Dimensions determining telepresence. In F. Biocca \& M. R. Levy (Eds.), Communication in the age of virtual reality (pp. 33-56). Hillsdale, NJ: Lawrence Erlbaum.

Stone, R. J. (2001). Haptic feedback: A brief history from telepresence to virtual reality. Haptic Human-Computer Interaction, 1-16. doi:10.1007/3-540-44589-7_1

Thelen, E. (1995). Time-scale dynamics in the development of an embodied cognition. In R. Port \& T. van Gelder (Eds.), Mind In Motion. Cambridge, MA: MIT Press.

Thelen, E., Schöner, G., Scheier, C., \& Smith, L. B. (2001). The dynamics of embodiment: a field theory of infant perseverative reaching. The Behavioral and Brain Sciences, 24(1), 1-34; discussion 34-86. doi:10.1017/\$0140525X01003910

Thelen, E., \& Smith, L. B. (1994). A dynamic systems approach to the development of cognition and action. Journal of Cognitive Neuroscience (Vol. 512). doi:10.1162/jocn.1995.7.4.512

Varela, F. J., Thompson, E., \& Rosch, E. (1991). The Embodied Mind: Cognitive Science and Human Experience. The embodied mind Cognitive science and human experience. Cambridge, MA: The MIT Press.

Wilson, M. (2002). Six views of embodied cognition. Psychonomic Bulletin \& Review, 9(4), 625-636. doi:10.3758/BF03196322 
Wilson, R. A., \& Foglia, L. (2011). Embodied Cognition. The Stanford Encyclopedia of Philosophy.

Retrieved

from

http://plato.stanford.edu/archives/fall2011/entries/embodied-cognition

Won, A. S., Bailenson, J., Lee, J., \& Lanier, J. (2015). Homuncular Flexibility in Virtual Reality. Journal of Computer-Mediated Communication, doi:10.1111/jcc4.12107

Yee, N., \& Bailenson, J. (2007). The Proteus Effect: The effect of transformed selfrepresentation on behavior. Human Communication Research, 33(3), 271-290. doi:10.1111/j.1468-2958.2007.00299.x 